\title{
A Novel Electric Insulation String Structure with High- Voltage Insulation and Wireless Power Transfer Capabilities
}

DOI:

10.1109/TPEL.2017.2706221

Link to publication record in Manchester Research Explorer

Citation for published version (APA):

Zhang, C., Lin, D., \& Hui, S. Y. R. (2017). A Novel Electric Insulation String Structure with High-Voltage Insulation and Wireless Power Transfer Capabilities. IEEE Transactions on Power Electronics, 33(1), 87-96.

https://doi.org/10.1109/TPEL.2017.2706221

\section{Published in:}

IEEE Transactions on Power Electronics

\section{Citing this paper}

Please note that where the full-text provided on Manchester Research Explorer is the Author Accepted Manuscript or Proof version this may differ from the final Published version. If citing, it is advised that you check and use the publisher's definitive version.

\section{General rights}

Copyright and moral rights for the publications made accessible in the Research Explorer are retained by the authors and/or other copyright owners and it is a condition of accessing publications that users recognise and abide by the legal requirements associated with these rights.

\section{Takedown policy}

If you believe that this document breaches copyright please refer to the University of Manchester's Takedown Procedures [http://man.ac.uk/04Y6Bo] or contact uml.scholarlycommunications@manchester.ac.uk providing relevant details, so we can investigate your claim.

\section{OPEN ACCESS}




\title{
A Novel Electric Insulation String Structure with High-Voltage Insulation and Wireless Power Transfer Capabilities
}

\author{
Cheng Zhang, Member, IEEE, Deyan Lin, Member, IEEE, Niang Tang, and S. Y. R. Hui, Fellow, IEEE
}

\begin{abstract}
High-voltage insulation strings are commonly used to hold high-voltage electric cables and electrically isolate them from the grounded transmission tower. In this paper, a novel concept of an electric insulation string with (i) high-voltage insulation (HVI) and (ii) wireless power transfer (WPT) capabilities is presented. Based on the concept of the domino-resonator WPT system, this new structure consists of coil-resonators embedded inside totally sealed insulation discs, which are then connected in series to form the new insulation string structure with the simultaneous HVI and WPT functions. This structure allows energy harvested from the a.c. magnetic field around the high-voltage cable to be transmitted wirelessly to power an online monitoring system in high-voltage transmission tower continuously, thereby reducing the storage requirements of the battery. The design and analysis of this new WPT structure based on the dimensions of commercially available high-voltage insulation rod are included. Practical measurements obtained from a hardware prototype of about $25 \mathrm{~W}$ have been obtained to confirm the WPT capability of the proposal. An energy efficiency over $60 \%$ has been achieved for a transmission distance of $1.1 \mathrm{~m}$ over a wide range of load.
\end{abstract}

Index Terms - wireless power transfer, High-voltage insulation string, magnetic resonance

\section{INTRODUCTION}

$\mathrm{T}_{\mathrm{p}}^{\mathrm{h}}$ he dawn of the Smart Grid and Internet of Things eras has prompted active research in recent years to set up online

C. Zhang was with the Department of Electrical and Electronic Engineering of the University of Hong Kong and is now with the Research Laboratory of Electronics, Massachusetts Institute of Technology, USA (email:guszhang@mit.edu).

D. Lin is with the School of Automation, Wuhan University of Technology, Wuhan, China and was with the Department of Electrical and Electronic Engineering, The University of Hong Kong, Pokfulam, Hong Kong (e-mail: deyanlin@whut.edu.cn).

N. Tang is with Electric Power Research Institute of Guangdong Power Grid Co., Ltd., Guangzhou, China. (e-mail: tangniang84@163.com).

S. Y. R. Hui is with the Department of Electrical and Electronic Engineering, Imperial College London, London SW7 2AZ, U.K., and also with the Department of Electrical and Electronic Engineering, The University of Hong Kong, Pokfulam, Hong Kong (e-mail: ronhui@eee.hku.hk). monitoring systems for power transmission systems. Such monitoring systems are particularly important and critical to some regions such as China which suffered several large-scale blackouts in recent years due to heavy snow storms in central and northern China [1] and typhoons in southern China [2]. The 2008 power blackout in China [1] has resulted in a total financial loss exceeding RMB 100 billion (approx. US\$ 15 billion) [7]. The seriousness of the power blackout problems in China is reflected in our literature review using IEEE Xplore that the majority of recent publications (since 2008) related to online monitoring research of power transmission towers actually came from China. Online monitoring systems for power transmission towers and cables cover a range of monitoring services such as electric parameters (e.g. voltage, current, phase angle and power) [3], mechanical parameters (e.g. tower structure [4], cable galloping, ice/snow thickness [5]-[7] and wind-induced mechanical vibration of transmission tower [8]), thermal parameters (e.g. cable temperature) [4] and weather information (e.g. wind speed, temperature and lightning and pollution level) [7],[9]-[10] as well as anti-theft monitoring [11]. With increasing requirements for online monitoring, there is a need for providing reliable power supply to power the monitoring instruments. In the past, solar power was the dominant power source. However, with several years of practical installations, power companies such as Guangdong Power have concluded that solar power is not the optimal solution for several reasons. Firstly, there are prolonged periods of rainy and cloudy days that make solar power alone unsuitable from a reliability point of view. Secondly, solar energy harvesting is only possible during day time when the weather is good, meaning that the size of the battery storage has to be large. In view of the increasing demand for powering online monitoring systems for power transmission towers and transmission lines, this project focuses on:

(i) "Reliable and continuous" energy harvesting from the HV transmission lines;

(ii) "High-efficiency wireless power transfer (WPT)" between any two points that require large creepage distance for $\mathrm{HV}$ insulation reasons.

A literature review conducted for this project indicates that energy harvesting can be achieved via photovoltaic (PV), wind, electric field and magnetic field for power transmission systems. So far, very limited work has been reported on techniques for transferring power over the creepage distance 
(typically from tens of centimeters to a few meters) in HV power transmission towers and cables. The only exception seems to be the microwave technique mentioned in [12], in which microwave repeaters are used to transmit power harvested from the power cables from one point to another. Therefore, technology for safe and efficient power transfer over long creepage distance in HV power transmission systems is a largely unchartered research area.

Mid-range WPT techniques have been proposed in the last decade. The magnetic resonance principle used recently in [13] was not new because Tesla used magnetic resonance in his early WPT experiments [25]. The limitation in [13] is that it adopts the Maximum Power Transfer Principle. For any circuit that operates with the Maximum Power Transfer Theorem via impedance matching with the source impedance, there is an inherent limitation that the energy efficiency of the system cannot be higher than $50 \%$. For a transmission distance of about $2 \mathrm{~m}$ and using coils with large diameters, the system energy efficiency in [13] is only $15 \%$. This serious limitation has been explained in a review paper [14]. A pair of dipole coils have been adopted for WPT of $209 \mathrm{~W}$ over 5 meters at an energy efficiency of $8 \%$ [26]. On the other hand, the wireless domino-resonator systems have been practically proven [15][18] to be a highly efficient way to transfer wireless power over a few meters. Unlike the proposal in [13], the wireless domino-resonator systems adopt the Maximum Energy Efficiency Principle and can achieve an overall system energy efficiency higher than $50 \%$.

In this paper, the domino-resonator concept is incorporated into a new structure of electric insulation rod or string which offers the dual capabilities of high-voltage insulation and wireless power transfer. Coil-resonators are resonant tanks formed by connecting a coil (inductor) and a resonant capacitor. They can be embedded in HV insulation discs to form a new insulation string with high-voltage insulation (HVI) and wireless power transfer (WPT) capabilities. For the first time, coil-resonators are designed to fit into the interior space of commercially available high-voltage insulator rod with standard dimensions for high-voltage insulation. A hardware prototype with rated power of $25 \mathrm{~W}$ has been constructed for practical evaluation so that the WPT capability of the insulation rod can be studied in a realistic manner. Experimental results show that an energy efficiency above $60 \%$ can be achieved for WPT for a transmission distance of $1.1 \mathrm{~m}$. This paper is an extended version of a short conference paper previously presented in [19]. The analysis points to a new design approach to operating the system within a high energy efficiency region in order to avoid problem arising from parametric tolerance. A full section on experimental verification is included.

\section{REQUIREMENTS OF ONLINE MONITORING SYSTEM FOR POWER TRANSMISSION SYSTEMS}

Previous online monitoring was powered by photovoltaic systems (PV) which have several limitations. Firstly, energy harvesting is limited to a few hours each day and is ineffective in prolonged period of cloudy or rainy weather. Secondly, the short duration of solar energy harvesting means that large battery storage is required. The failure to monitor faults in the prolonged snow storm period in 2008 exposed these fatal problems. Take a simple example. If a PV system can harvest an average of 6 hours of solar energy each day under normal situation, the battery needs to provide 450VAh to power an online monitoring equipment of $25 \mathrm{~W}$ for the remaining 18 hours. Under the same normal situation, the proposed system harvests energy continuously from the magnetic field around the transmission cable and therefore theoretically does not need any battery storage. In practice, a small battery is needed so that the online monitoring system can wirelessly transmit fault signals and locations to the control center if abnormal situation occurs.

The new concept of this proposal can be illustrated with the aid of a practical transmission tower example shown in Fig.1. The magnetic field generated by the transmission cable (marked as (1) in Fig.1) can be "continuously" harvested with a transformer and a power converter. The harvested energy can be stored in a supercapacitor and/or a rechargeable battery. Because energy can be harvested from the power cable continuously without any time constraint (such as day time only for PV panels), the storage capacity of the supercapacitor and/or battery can be much smaller than that for a solar power system. As the online monitoring system has to be mounted on the Transmission Tower (marked as (2) in Fig.1) which is earthed, there is a considerable transmission distance between the energy-harvesting point (1) and the energy-receiving point (2). According to IEC 60137 standard [20], the creepage distance depends on the voltage and the air pollution conditions as listed in Table I. Typical power requirements provided by a power company (Guangdong Power Grid Corporation, a subsidiary of China Southern Power Grid) are listed in Table II.

\section{TABLE I IEC 60137 STANDARD ON CREEPAGE DISTANCE FOR VOLTAGE $>1000 \mathrm{~V}$}

\begin{tabular}{|c|c|}
\hline Condition & Creepage \\
\hline Normal & $16 \mathrm{~mm} / \mathrm{kV}$ \\
\hline Medium pollution & $20 \mathrm{~mm} / \mathrm{kV}$ \\
\hline Heavy pollution & $25 \mathrm{~mm} / \mathrm{kV}$ \\
\hline Very Heavy Pollution & $31 \mathrm{~mm} / \mathrm{kV}$ \\
\hline
\end{tabular}

TABLE II TYPICAL POWER REQUIREMENTS OF ONLINE MONITORING SYSTEMS

(COURTESY OF GUANGDONG POWER GRID CORPORATION)

\begin{tabular}{|c|c|c|}
\hline & $\begin{array}{l}\text { Sleep } \\
\text { mode }\end{array}$ & Active mode \\
\hline Video & $2 \mathrm{~W}$ & $12 \mathrm{~W}$ \\
\hline Snow monitoring & $1 \mathrm{~W}$ & $3.5 \mathrm{~W}$ \\
\hline Micro-meteorological monitor & $1 \mathrm{~W}$ & $3 \mathrm{~W}$ \\
\hline Micro-processing unit & $10 \mathrm{~mW}$ & $50 \mathrm{~mW}$ \\
\hline Total: & $4.01 \mathrm{~W}$ & $18.55 \mathrm{~W}$ \\
\hline
\end{tabular}




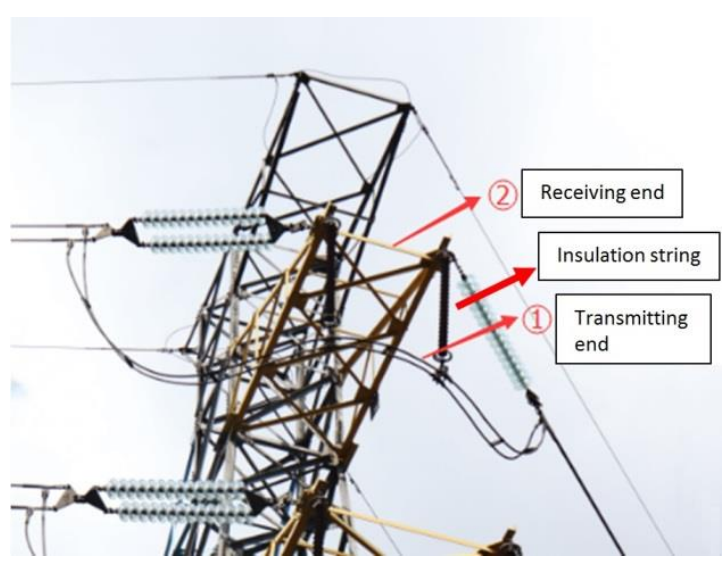

Fig.1 Energy harvesting point at the shielded cable: (1) and Energy receiving point; (2)at the tower structure. [Note: there is a large creepage distance between (1) and (2)

Fig. 1 shows an example of rigid insulation strings holding the HV transmission lines to the Transmission Tower. For transmission distance of this magnitude, traditional 2-coil and 4-coil WPT techniques cannot achieve high efficiency because such efficiency is inversely proportional to the square of the transmission/insulation distance.

The new concept of WPT system for this HV application with large creepage distance is shown in Fig.2. This concept consists of

(i) a magnetic field energy harvester with an energy storage element (such as supercapacitors and/or rechargeable batteries),

(ii) a dc-ac high-frequency power inverter driving a transmitter coil-resonator,

(iii) a novel insulation rod/string with embedded relay coil-resonators;

(iv) a high-frequency energy-receiving circuit with a receiver coil resonator.

In this study, the research focuses only on the new insulator string with embedded coil-resonators for WPT. The frontstage energy harvesting module and the high-frequency ac-dc converter in the receiver stage will be covered in future research.

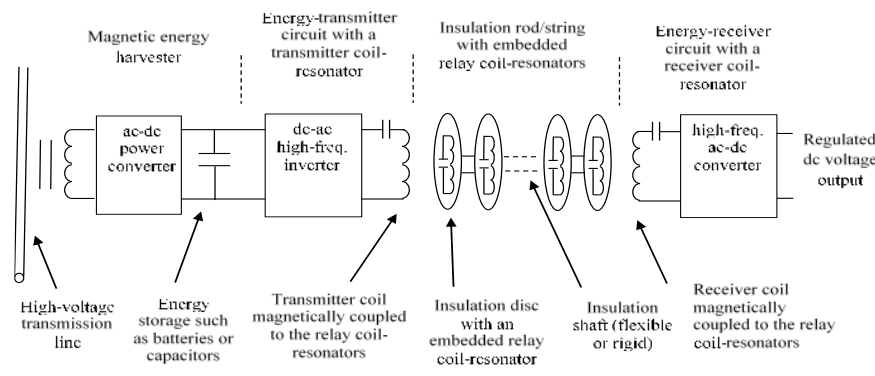

Fig.2 Schematic of the Novel Wireless Power Transfer System for Power Systems [21]
The novel insulation string consists of a series of insulation discs. If the discs are linked with rigid insulation shaft, a rigid insulation string (also known as "insulation rod") is formed. If the discs are linked with a flexible insulation shaft, the structure is called a flexible insulation string. The transmitter coil-resonator is arranged in such a way that it is placed close to and magnetically coupled to the coil-resonator in the first insulation disc on the transmitter side. Similarly, the last insulation disc of the insulation rod/string is placed close to the receiver's coil-resonator for close magnetic coupling. The coil-resonators embedded in the discs between the transmitter module and receiver module are used as relay or repeater coilresonators. The operation of the proposed insulation rod/string is based on the wireless domino-resonator systems [15][16], which offer good compromise of high energy efficiency and transmission distance for mid-range WPT applications.

\section{ANALYSIS AND DESIGN OF AN INSULATION STRING WITH HVI AND WPT CAPABILITIES}

\section{A. Modeling of the Insulation String with Embedded Coil- Resonators}

Fig. 3 shows a typical structure of stackable discs in the form of an insulation string. Each disc has an embedded coil connected in series with a capacitor, forming an inductivecapacitive (LC) resonant tank (called coil-resonators hereafter). The coil-resonator is totally enclosed inside the insulation disc so that it is not affected by dust and water. The resonant frequency of this resonant tank in each disc should be identical. When many discs are connected in series as shown in Fig.4, a new form of insulation string with HVI and WPT functions can be realized.

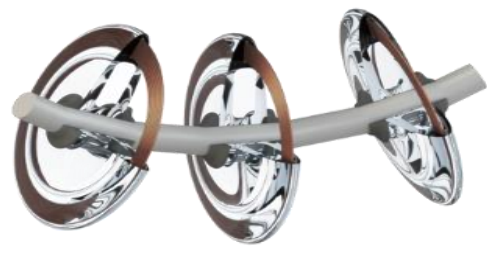

Fig.3 Schematic of a "novel flexible insulation string" consisting of novel discs (with a section of the toughed glass removed to show the embedded copper coil of the resonator)

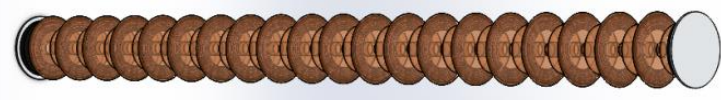

Fig.4 Novel insulation string with (i) High Voltage Insulation (HVI) \& (ii) Wireless Power Transfer (WPT) capabilities

Consider a domino wireless power transfer system consisting of $n$ coils as shown in Fig.5. If we assume $L_{i}$ is the self-inductance of the $i^{\text {th }}$ coil, $R_{i}$ is the coil resistance of the $i^{\text {th }}$ coil, and $M_{i j}$ is the mutual-inductance between the $i^{t h}$ coil and the $j^{\text {th }}$ coil, then the system could be described in matrix equation (1). 


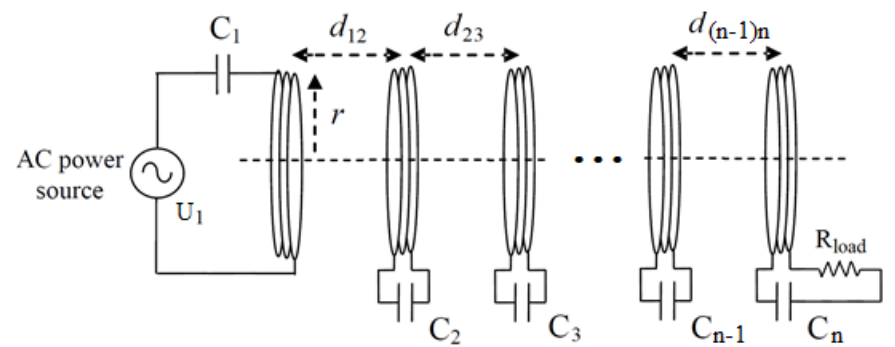

Fig.5 An n-coil domino system for wireless power transfer

$\left.\left[\begin{array}{c}U_{1} \\ 0 \\ \vdots \\ 0 \\ 0\end{array}\right]=\left[\begin{array}{ccccc}R_{1}+j\left(\omega L_{1}-\frac{1}{\omega C_{1}}\right) & j \omega M_{12} & \cdots & j \omega M_{1(n-1)} & j \omega M_{1 n} \\ j \omega M_{21} & R_{2}+j\left(\omega L_{2}-\frac{1}{\omega C_{2}}\right) & \cdots & j \omega M_{2(n-1)} & j \omega M_{2 n} \\ \vdots & \vdots & \ddots & \vdots & \vdots \\ j \omega M_{(n-1) !} & j \omega M_{(n-1) 2} & \cdots & R_{n-1}+j\left(\omega L_{n-1}-\frac{1}{\omega C_{n-1}}\right) & j \omega M_{(n-1) n} \\ j \omega M_{n 1} & j \omega M_{n 2} & \cdots & j \omega M_{n(n-1)} & R_{n}+R_{l}+j\left(\omega L_{n}-\frac{1}{\omega C_{n}}\right.\end{array}\right]\right)\left[\begin{array}{c}I_{1} \\ I_{2} \\ \vdots \\ I_{n-1} \\ I_{n}\end{array}\right]$

If all the parameters in the matrix in equation (1) are known, for a given frequency $f$, we can get the input impedance of the system by giving a certain input of $U_{l f}$, calculating the input current $I_{l f}$, and then,

$$
Z_{f}=\frac{U_{1_{f}}}{I_{1_{f}}}
$$

Hence, a set of impedance values at different frequencies can be obtained: $Z_{f_{1}}, Z_{f_{2}}, \cdots, Z_{f_{m}}$, where $f_{i}$ is one of the different frequencies, and $Z_{f_{i}}$ is the input impedance at $f_{i}$.

$$
\left(Z_{f_{1}}, Z_{f_{2}}, \cdots, Z_{f_{m}}\right)=f\left(\begin{array}{l}
L_{1}, L_{2}, \cdots, L_{n}, \\
M_{12}, M_{23}, \cdots, M_{(n-1) n}, \\
C_{1}, C_{2}, \cdots, C_{n}, \\
R_{1}, R_{2}, \cdots, R_{n}, \\
R_{\text {load }}
\end{array}\right)
$$

Since the coils in the domino system are identical to each other, the self-inductance of $L_{l}$ through $L_{n}$ can be treated as a constant value, and it could be accurately calculated [22]. The coil resistance, $R_{l}$ through $R_{n}$, can be considered as identical and it can be measured at the operating resonant frequency of the coil-resonator. Such coil resistance can be considered as a constant value if the wireless power transfer system is operated around the resonant frequency. All the measured parameters or the nominal value of the resonators are shown in Table I. Meanwhile, we can treat the mutual inductances $M_{12}, M_{23}, \ldots, M_{(n-1) n}$ as functions of distances between each coil pair, $d_{12}, d_{23}, \ldots, d_{(n-1) n}[23]$, then equation (3) can be replaced by equation (4):

$$
\left(Z_{f_{1}}, Z_{f_{2}}, \cdots, Z_{f_{m-1}}, Z_{f_{m}}\right)=f\left(\begin{array}{c}
L_{1}, L_{2}, \cdots, L_{n}, \\
d_{12}, d_{23}, \cdots, d_{(n-1) n}, \\
C_{1}, C_{2}, \cdots, C_{n}, \\
R_{1}, R_{2}, \cdots, R_{n}, \\
R_{\text {load }}
\end{array}\right)
$$

The energy efficiency of the insulation string with embedded coil-resonators is expressed as:

$$
\eta(f)=\frac{i_{n}^{2}(f) R_{\text {load }}}{i_{n}^{2}(f) R_{\text {load }}+\sum_{x=1}^{n} i_{x}^{2}(f) R_{x}}
$$

and the output power is:

$$
P_{\text {out }}(f)=i_{n}^{2}(f) R_{\text {load }}
$$

\section{B. Design of Coil-Resonators Based on Practical Insulator Strings}

The embeddable coil-resonators of the proposed insulation string with WPT and HVI capability should preferably be compatible with the dimensions of existing insulation strings commercially available. Fig. 6 shows a practical example of a commercially available insulation string [24]. It consists of a series of insulation discs with large diameter separated by insulation discs with small diameter. The dimensions of the insulation string structure in this investigation are given in Table III, in which the distances between adjacent disc-x and disc-y with large diameters (labelled as "B" in Fig.6) are tabulated as $\mathrm{d}_{\mathrm{xy}}$. The total distance of this example is $1.1 \mathrm{~m}$ and the diameter of the large disc is $0.2 \mathrm{~m}$. The coil-resonators are embedded only in the insulation discs of large diameters.

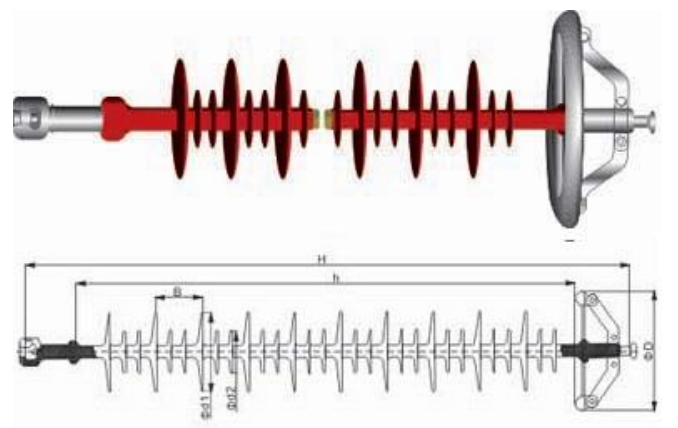

Fig.6 Typical dimensions of a commercial insulation string [24]

TABLE III DESIGN PARAMETERS

\begin{tabular}{|c|c|c|c|c|c|c|c|c|c|c|}
\hline $\begin{array}{c}\mathrm{d}_{12} \\
(\mathrm{~m})\end{array}$ & $\begin{array}{c}\mathrm{d}_{23} \\
(\mathrm{~m})\end{array}$ & $\begin{array}{c}\mathrm{d}_{34} \\
(\mathrm{~m})\end{array}$ & $\begin{array}{c}\mathrm{d}_{45} \\
(\mathrm{~m})\end{array}$ & $\begin{array}{c}\mathrm{d}_{56} \\
(\mathrm{~m})\end{array}$ & $\begin{array}{c}\mathrm{d}_{67} \\
(\mathrm{~m})\end{array}$ & $\begin{array}{c}\mathrm{d}_{78} \\
(\mathrm{~m})\end{array}$ & $\begin{array}{c}\mathrm{d}_{89} \\
(\mathrm{~m})\end{array}$ & $\begin{array}{c}\mathrm{d}_{910} \\
(\mathrm{~m})\end{array}$ & $\begin{array}{c}\mathrm{d}_{1011} \\
(\mathrm{~m})\end{array}$ & $\begin{array}{c}\mathrm{d}_{1112} \\
(\mathrm{~m})\end{array}$ \\
\hline 0.11 & 0.098 & 0.098 & 0.098 & 0.098 & 0.098 & 0.098 & 0.098 & 0.098 & 0.098 & 0.11 \\
\hline
\end{tabular}




\section{VERIFICATION AND EVALUATION OF THE WPT CAPABILITY}

\section{A. Practical Insulations String with coil-resonators}

Twelve coil-resonators are designed to fit into the dimensions of the insulation discs of large diameter (i.e. $200 \mathrm{~mm}$ ). The hardware setup is shown in Fig. 7. The energy efficiency of WPT system depends on the $k Q$ product, where $k$ is the coupling coefficient between adjacent magnetically coupled coils and $Q$ is the quality factor of the coil. It is therefore necessary to use operating frequency high enough to achieve high $Q$ factor within the capability of existing power electronics technology. The operating frequency is designed to be in the range from $300 \mathrm{kHz}$ to $500 \mathrm{kHz}$, which is within existing capability of switched mode power supplies.

The parameters of the coil-resonator are tabulated in Table IV. Coils of such dimensions can be accommodated by existing insulation discs. The self-inductance is about $155 \mu \mathrm{H}$ and the resonant capacitor is $1 \mathrm{nF}$. The targeted resonant frequency is about $400 \mathrm{kHz}$, at which the ac coil resistance is about $1.30 \Omega$ and the $Q$ factor is about 300. In order to improve the accuracy of the mathematical model, the actual capacitance values of the resonant capacitors and the separation distances between adjacent coil-resonators are measured and tabulated in Table V. These measured values are used to the computer-aided evaluation.

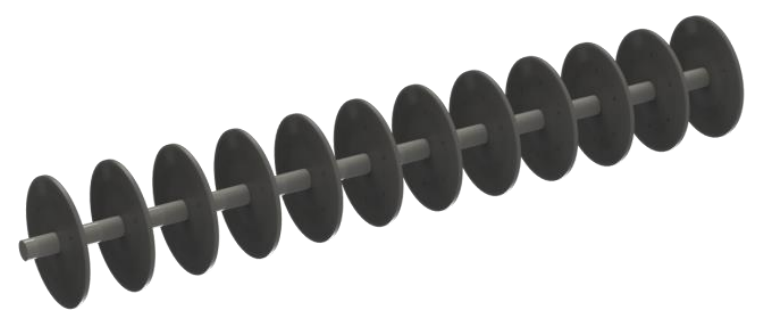

(a)

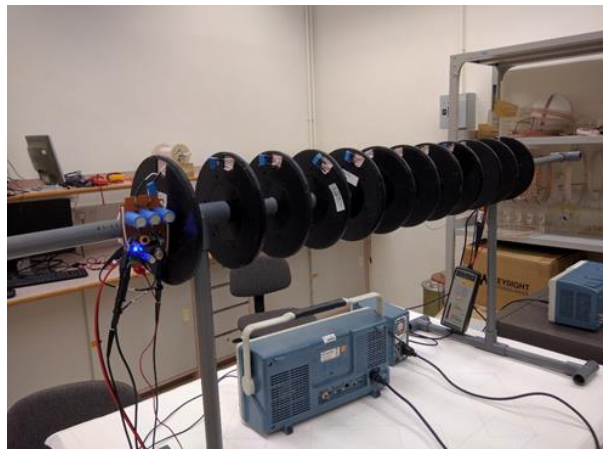

(b)

Fig.7 Prototype of 12-coil insulator wireless power transfer system: (a) sketch; (b) real prototype
TABLE IV PRAMETERS OF THE RESONATORS

\begin{tabular}{|c|c|}
\hline Outer Radius of Windings & $68 \mathrm{~mm}$ \\
\hline Inner Radius of Windings & $88 \mathrm{~mm}$ \\
\hline Number of turns & 24 \\
\hline Layer of the wire & 2 \\
\hline Structure of the Litz wire & $\begin{array}{c}\Phi 0.1 \mathrm{~mm}^{*} 120 \text { strans } \\
\text { Outer } \Phi 1.7 \mathrm{~mm}\end{array}$ \\
\hline Inductance (Calculated) & $155.0 \mathrm{uH}$ \\
\hline $\begin{array}{c}\text { Capacitance (Nominal value) } \\
\text { \#1 through \#12 }\end{array}$ & $1 \mathrm{nF}$ \\
\hline $\begin{array}{c}\text { Measured wire resistance } \\
\text { (at } 400 \mathrm{kHz} \text { ) }\end{array}$ & $1.30 \mathrm{Ohm}$ \\
\hline
\end{tabular}

TABLE V PRACTICAL PARAMETERS OF THE RESONANT CAPACITANCE \& SEPARATION DISTANCES

\begin{tabular}{|c|c|c|c|c|c|c|c|c|c|c|c|}
\hline \begin{tabular}{|c|}
$\mathrm{C}_{1}$ \\
$(\mu \mathrm{F})$ \\
\end{tabular} & $\begin{array}{c}\mathrm{C}_{2} \\
(\mu \mathrm{F})\end{array}$ & $\begin{array}{c}\mathrm{C}_{3} \\
(\mu \mathrm{F})\end{array}$ & $\begin{array}{c}\mathrm{C}_{4} \\
(\mu \mathrm{F}) \\
\end{array}$ & $\begin{array}{c}\mathrm{C}_{5} \\
(\mu \mathrm{F}) \\
\end{array}$ & $\begin{array}{c}\mathrm{C}_{6} \\
(\mu \mathrm{F}) \\
\end{array}$ & $\begin{array}{c}\mathrm{C}_{7} \\
(\mu \mathrm{F}) \\
\end{array}$ & $\begin{array}{c}\mathrm{C}_{8} \\
(\mu \mathrm{F})\end{array}$ & \begin{tabular}{|c}
$\mathrm{C}_{9}$ \\
$(\mu \mathrm{F})$ \\
\end{tabular} & $\begin{array}{c}\mathrm{C}_{10} \\
(\mu \mathrm{F}) \\
\end{array}$ & $\begin{array}{c}\mathrm{C}_{11} \\
(\mu \mathrm{F})\end{array}$ & \begin{tabular}{|l|}
$\mathrm{C}_{12}$ \\
$(\mu \mathrm{F})$ \\
\end{tabular} \\
\hline 1.05 & 1.01 & 1.03 & 1.02 & 1.02 & 1.03 & 1.01 & 1.03 & 1.04 & 0.99 & 0.98 & 1.06 \\
\hline $\begin{array}{l}\mathrm{d}_{12} \\
(\mathrm{~m})\end{array}$ & $\begin{array}{l}\mathrm{d}_{23} \\
(\mathrm{~m})\end{array}$ & $\begin{array}{l}\mathrm{d}_{34} \\
(\mathrm{~m}) \\
\end{array}$ & $\begin{array}{l}\mathrm{d}_{45} \\
(\mathrm{~m})\end{array}$ & $\begin{array}{l}\mathrm{d}_{56} \\
(\mathrm{~m}) \\
\end{array}$ & $\begin{array}{l}\mathrm{d}_{67} \\
(\mathrm{~m})\end{array}$ & $\begin{array}{l}\mathrm{d}_{78} \\
(\mathrm{~m})\end{array}$ & $\begin{array}{l}\mathrm{d}_{89} \\
(\mathrm{~m}) \\
\end{array}$ & $\begin{array}{l}\mathrm{d}_{910} \\
(\mathrm{~m})\end{array}$ & $\begin{array}{c}\mathrm{d}_{1011} \\
(\mathrm{~m})\end{array}$ & $\begin{array}{c}\mathrm{d}_{1112} \\
(\mathrm{~m})\end{array}$ & \\
\hline 0.113 & 0.099 & 0.095 & 0.098 & .100 & 0.0 & 09 & 0.098 & 0.095 & 0.085 & 0.117 & \\
\hline
\end{tabular}

\section{B. Computer-aided Analysis with Practical Verification}

i) Computed and Experimental Input Impedance and Input Phase Angle

In order to check the accuracy of the mathematical model described in the last section, the input impedance and the input phase angle of the insulation string prototype are measured with steps of $1 \mathrm{kHz}$ increment from $300 \mathrm{kHz}$ to $500 \mathrm{kHz}$, when the last coil-resonator is loaded with a fixed resistive load $R_{\text {laod }}$ of $10 \Omega$. As multiple coil-resonator system is a highorder system with multiple resonant points, 200 sets measurements from $300 \mathrm{kHz}$ to $500 \mathrm{kHz}$ are captured with a high-speed digital oscilloscope and transferred to a computer for analysis. Fig.8 shows the simulated and experimental results of the impedance (Z_exp and Z_sim) over the specific frequency range. The corresponding simulated and measured phase angle between input voltage and current are shown in Fig.9. These results indicate that the overall impedance has a transitional change from being capacitive-resistive (below 380 $\mathrm{kHz}$ ) to resistive (at around $380 \mathrm{kHz}$ to $400 \mathrm{kHz}$ ) and then inductive-resistive (above $400 \mathrm{kHz}$ ) as the frequency increases from $300 \mathrm{kHz}$ to $500 \mathrm{kHz}$. These measurements show that the resonant frequency of the overall system is within $380 \mathrm{kHz}$ to $400 \mathrm{kHz}$, which is close to the targeted frequency of $400 \mathrm{kHz}$. The good agreements between the experimental and simulated results confirm the validity of the mathematical model. This provides the confidence that the mathematical model can be used to optimize the system operating conditions. 


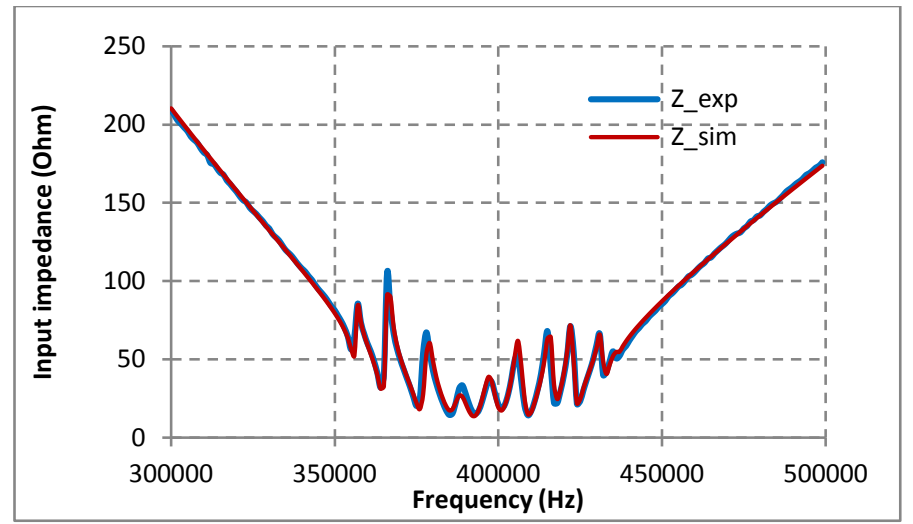

Fig. 8 Experimental and simulated values of the input impedance

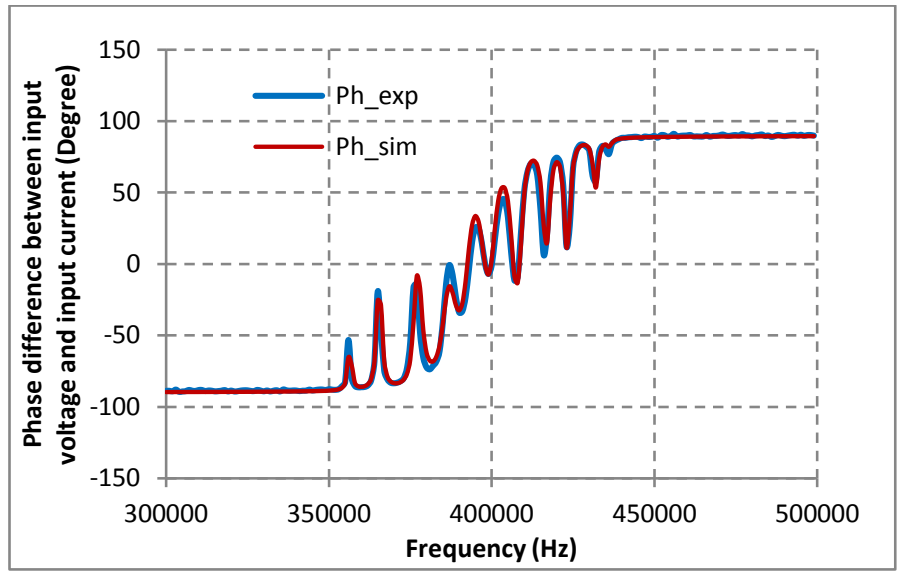

Fig.9 Experimental and simulated values of the phase angle of the input impedance

\section{ii) Computed and Experimental Energy Efficiency}

Computer analysis can be used to explore the relationships among the energy efficiency, operating frequency and load resistance for optimal operation in a 3-dimensional (3-D) manner. In the practical setup, a high-frequency power source is used to drive the transmitter coil, while the last resonator is loaded with a resistor. Because no power converter is involved in the process, the energy efficiency is calculated from the ratio of the load power and the input power to the transmitter coil. Under an excitation voltage of $28 \mathrm{~V}$, such $3-\mathrm{D}$ plot is shown in Fig. 10(a). This result shows that energy efficiency exceeding $60 \%$ is possible for transmitting over $25 \mathrm{~W}$ over an overall transmission distance of $1.1 \mathrm{~m}$ based on the proposal insulation string structure with large insulation discs embedded with coil-resonators. In order to examine the details of this result, the energy efficiency of the prototype is included in a 2-D contour plot as shown in Fig. 10(b). This computed result indicates that high energy efficiency can be achieved for this prototype over a wide load resistance range with the frequency range of $380 \mathrm{kHz}$ and $400 \mathrm{kHz}$. For example, if an operating frequency of $393 \mathrm{kHz}$ is selected, high energy efficiency can be achieved for a load resistance range from about $8 \Omega$ to $50 \Omega$.
For a load resistance of $50 \Omega$, the computed and measured energy efficiency curves over a frequency range from $340 \mathrm{kHz}$ to $440 \mathrm{kHz}$ are plotted in Fig.11. The good agreement between the computed and practical measurement confirm that (i) the accuracy of the mathematical model is acceptable and (ii) energy efficiency exceeding $60 \%$ is practically feasible for a transmission distance of $1.1 \mathrm{~m}$.

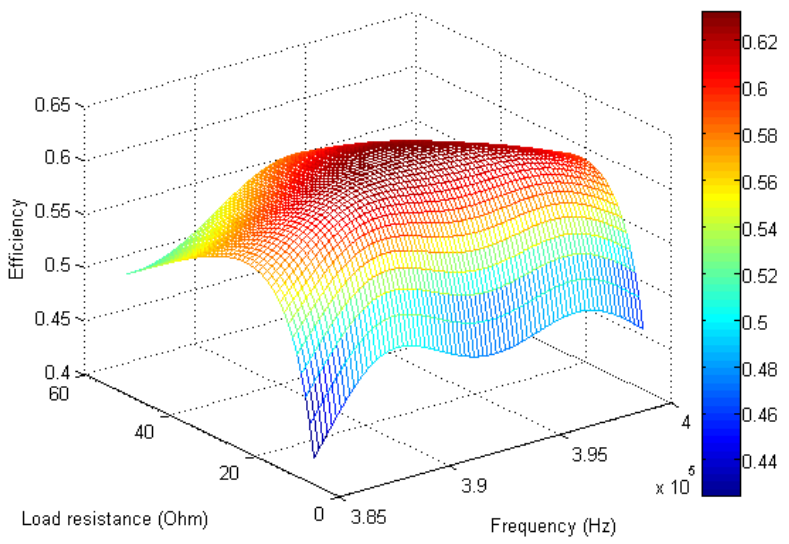

(a)

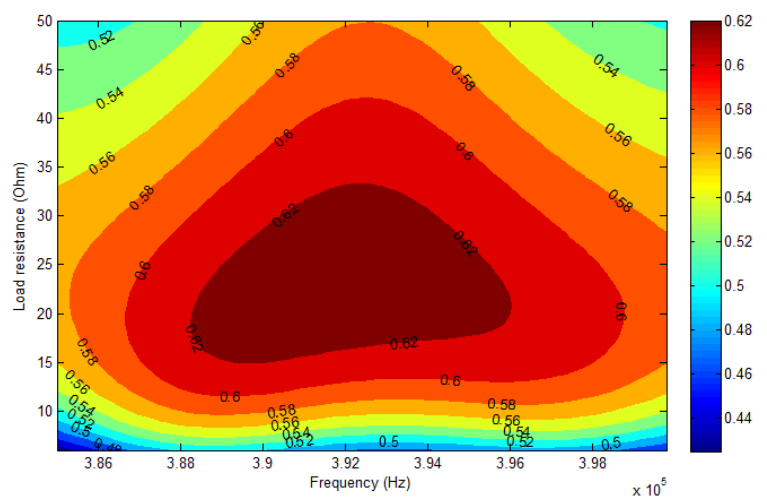

(b)

Fig.10 Computed energy efficiency of the prototype as a function of operating frequency and load resistance (Input voltage: 28V): (a) 3-D plot; (b) 2-D contour plot.

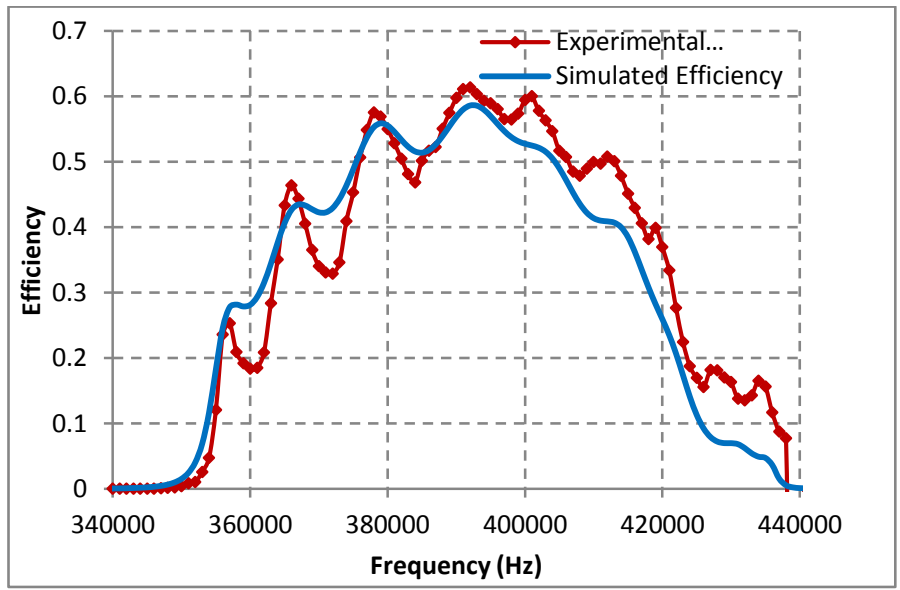

Fig.11 Computed and experimental energy efficiency of the prototype load with a resistor of $50 \Omega$. 
The variation of the energy efficiency as a function of the distance (or number of insulation discs) has been evaluated. The load is placed at each insulated disc from the second to the last coil-resonator in a 12-coil WPT system (with a total distance of $1.1 \mathrm{~m}$ between the transmitter coil-resonator to the last receiver coil-resonator). The energy efficiency curve is plotted in Fig.15. It can be seen that the energy efficiency varies from about $90 \%$ to about $60 \%$ in this practical prototype. One extra test has also been conducted in a 12-coil system with the 6th coil open-circuited (i.e the transmission distance between the $5^{\text {th }}$ and $7^{\text {th }}$ coil-resonator is now doubled) This special energy efficiency is included in Fig.12. It is noted that wireless power can still be transmitted to the load, but the energy efficiency will drop from about $60 \%$ to about $20 \%$.

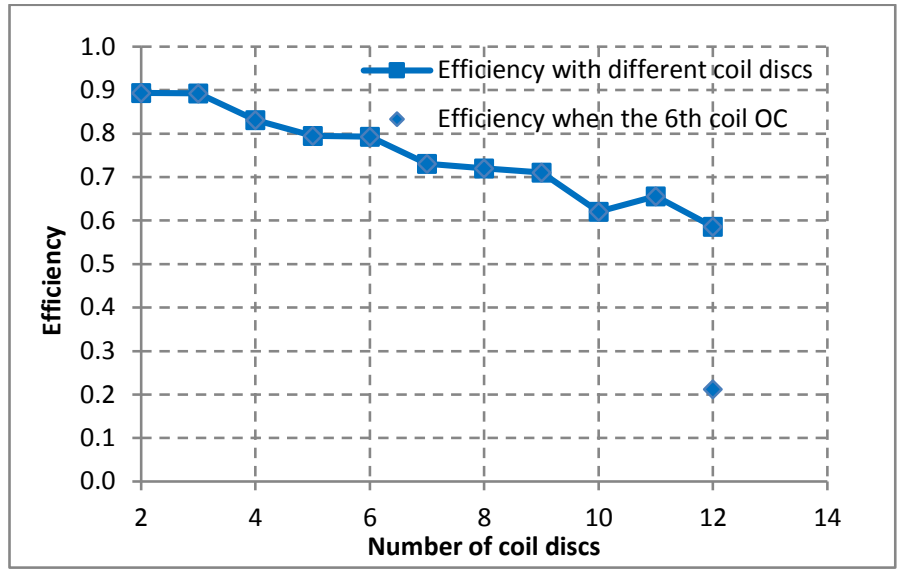

Fig. 12 Energy efficiency with different coil discs at operating frequency of $393 \mathrm{kHz}$ with a load resistance of $50 \mathrm{Ohm}$ (with one extra measured point of energy efficiency when the 6th coil of a 12-coil WPT system open-circuited)

iii) Computed and Measured Output Power

The output power as a function of the operating frequency and load resistance has also been computed as shown in a 3-D plot in Fig. 13(a). The phenomenon of frequency splitting can be observed. In order to make it easy to design the operating range, the output power is displayed in a 2-D plane against the color scale in Fig. 13(b), in which the load resistance range from $8 \Omega$ to $45 \Omega$ is highlighted in a solid line at $393 \mathrm{kHz}$.

Practical tests have been conducted with the prototype operating along the load resistance range from $8 \Omega$ to $45 \Omega$ at $393 \mathrm{kHz}$. The experimental and simulated output power are plotted in Fig. 14. It is noted that the practical output power is slightly less than the predicted one. At high-frequency operation, some inductive effect exists in the ceramic resistor. Such parasitic inductance increases the effective impedance of the output load and reduces the output power. However, the overall trend of the actual power is consistent with the predicted curve. The corresponding energy efficiency results over this load range are shown in Fig. 15. These results confirm that an energy efficiency exceeding $60 \%$ is possible over a wide load range.

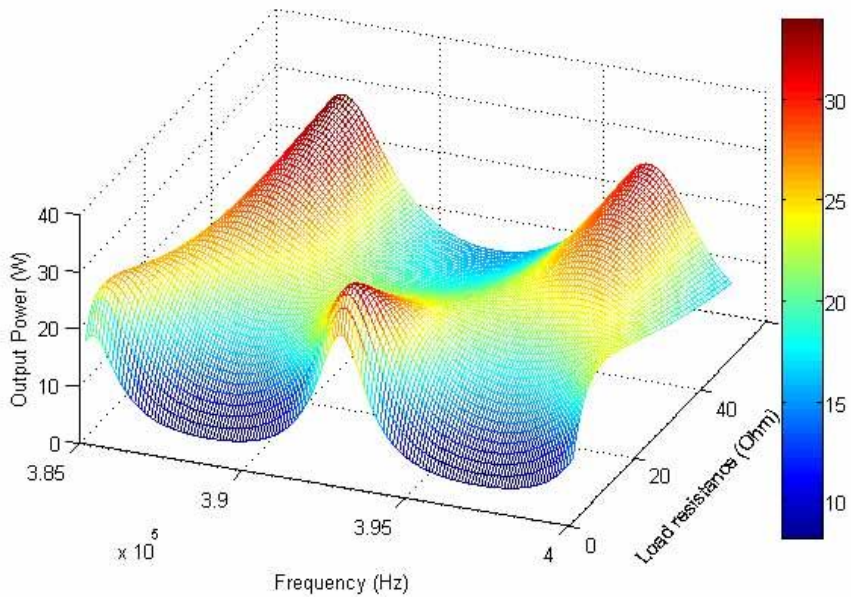

(a)

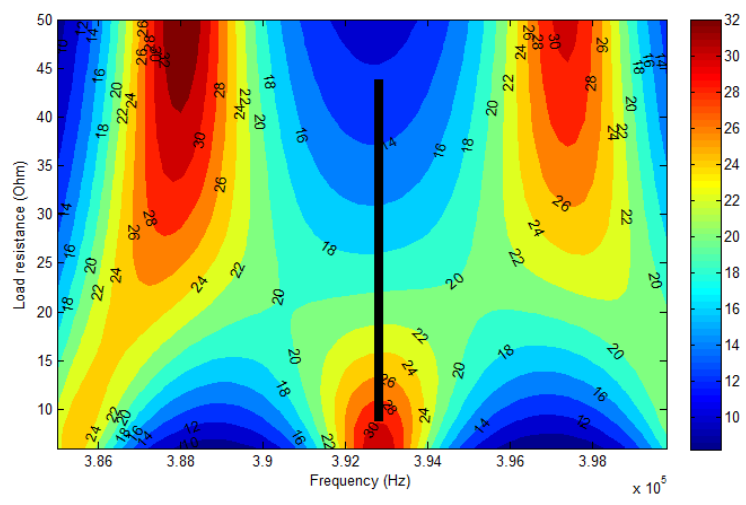

(b)

Fig.13 Computed output power as a function of the operating frequency and load resistance (Input voltage: 28V): (a) Computed output power in 3-D plot; (b) Computed output power in 2-D contour plot. [Note: The bold line illustrates the load resistance range under consideration in Fig.14 and Fig.15]

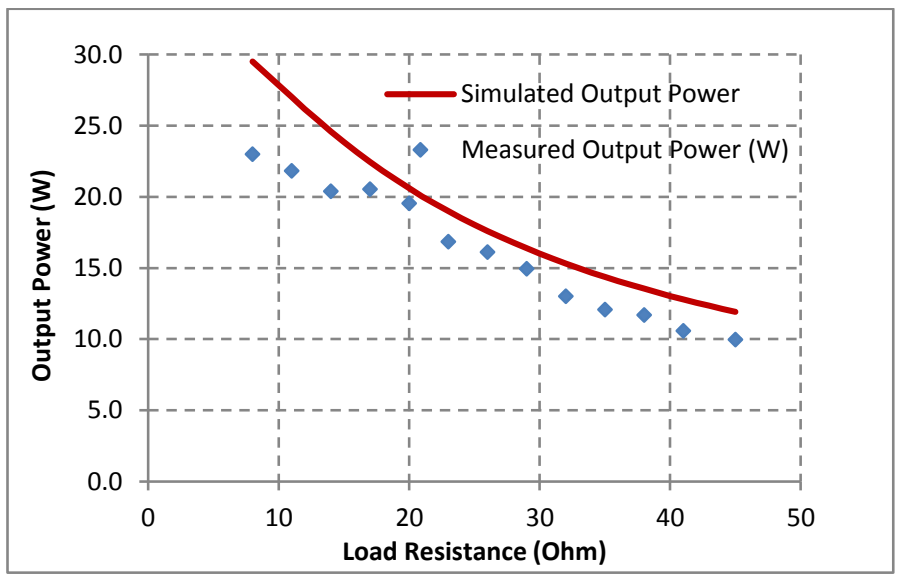

Fig. 14 Experimental output power over a range of load resistance at an operating frequency of $393 \mathrm{kHz}$ and an input voltage of $28.3 \mathrm{~V}$. [Note: Parasitic inductance in the load resistor at $393 \mathrm{kHz}$ is not considered in the simulation] 


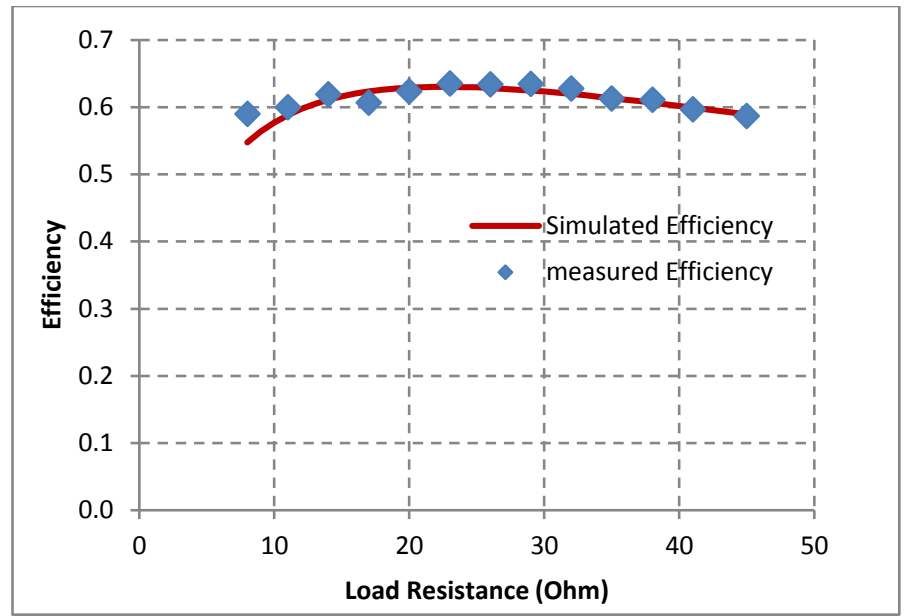

Fig. 15 Experimental energy efficiency over a range of load resistance at an operating frequency of $393 \mathrm{kHz}$ and an input voltage of $28.3 \mathrm{~V}$

\section{Practical Demonstration of Powering Online Monitoring Camera}

The wireless power transfer prototype has been used to drive an IP camera (Brand: WIRYTH) as shown in Fig. 16. An ac power source of $20 \mathrm{~V}$ at $393 \mathrm{kHz}$ is used to drive the insulation string WPT system. A simple ac/dc converter and a buck converter are used to maintain the output voltage to $5 \mathrm{~V}$ DC to fit the requirement of the IP camera. The normal operating current of the IP camera is $300 \mathrm{~mA}$ and the maximum current is $1300 \mathrm{~mA} @ 5 \mathrm{~V}$ input when the camera is rotating. A video of the live demonstration is included in the attached video file.

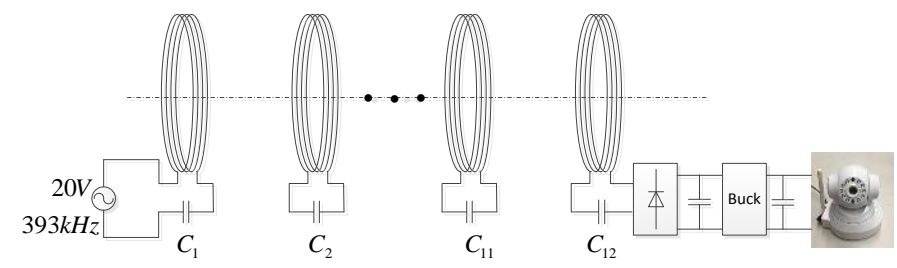

Fig.16 The diagram of the insulator wireless power transfer system

\section{Simulation Study OF Electric Field Distribution}

While the main theme of this study focuses on the WPT capabilities of this proposed idea, a finite-element simulation study has been conducted to evaluate the electric field distribution of the proposed insulation string with and without the embedded coil-resonators. Finite element analysis (FEA) is carried out on a $110 \mathrm{kV}$ insulator prototype. The dimension of the prototype is based on that of a commercially available $110 \mathrm{kV}$ composite insulator which has 12 pieces of large sheds. The parameters of a practical $110 \mathrm{kV}$ composite insulator (Fig.17) listed in TABLE VI are used in the finite-element simulation.

Fig. 17 shows the 3-D structure and 2-D simulation model of the prototype. When adding coils for wireless power transfer, two more sheds are added for holding the transmitter coil and the receiver coil. In the analysis, the insulator string with embedded coils and 2 more sheds are compared with the original insulator. Applying the same $180 \mathrm{kV}$ peak voltage to these two insulators, the E-field distribution situations are compared in Figs. 18-20. Fig. 18 shows that the E-field distribution over the whole area is more even for the insulator string with embedded coils. The curves in Fig. 19(a) and Fig. 19(b) also indicate that the E-field intensity at two ends of the insulator string is lower for the case with the embedded coilresonators. Fig.20 shows that the voltage distribution has a similar pattern for with and without the embedded coilresonators. Therefore, it can be inferred that adding coils to the insulator does not seem to degrade the whole E-field or voltage distribution. Instead, the coils near the corona rings might have a function of further evening the E-field distribution at two ends. Practical high-voltage tests will be conducted in the future to confirm these simulation results.

\section{TABLE VI PARAMETERS OF THE 110KV COMPOSITE} INSULATOR

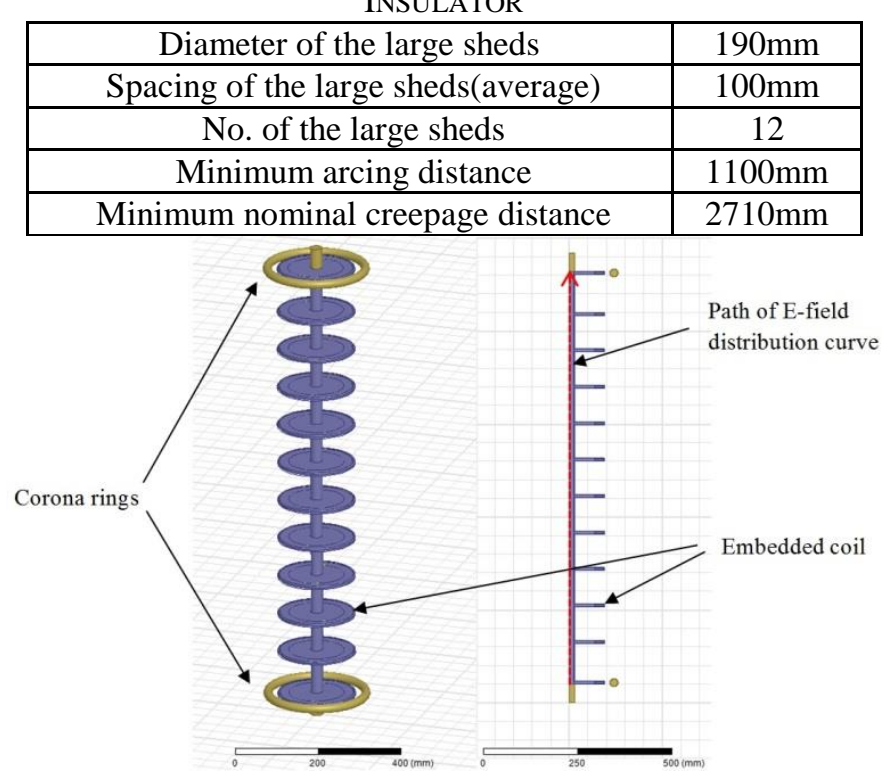

Fig.17 3-D structure (left) and 2-D Finite-element model (right) of the insulator string

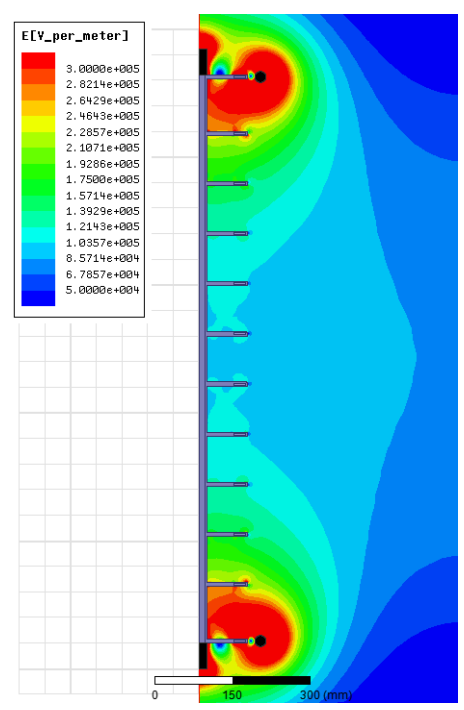

(a)

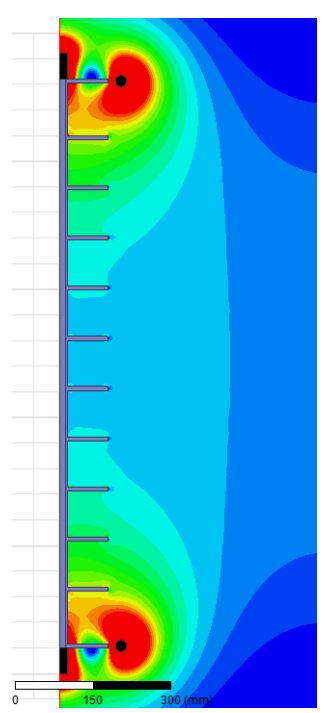

(b)
Fig.18 Simulated electric field distributions of the insulation strings: (a) with and (b) without embedded coil-resonators. 


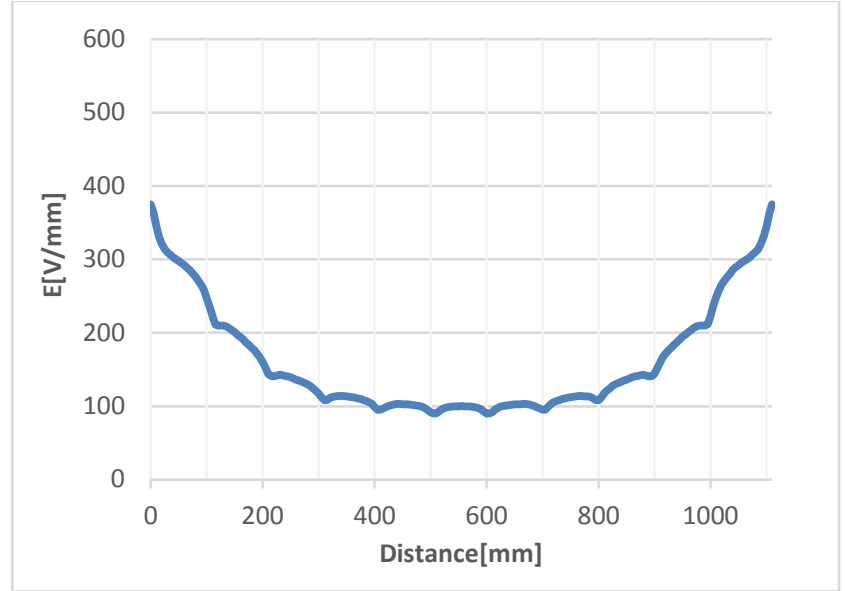

(a)

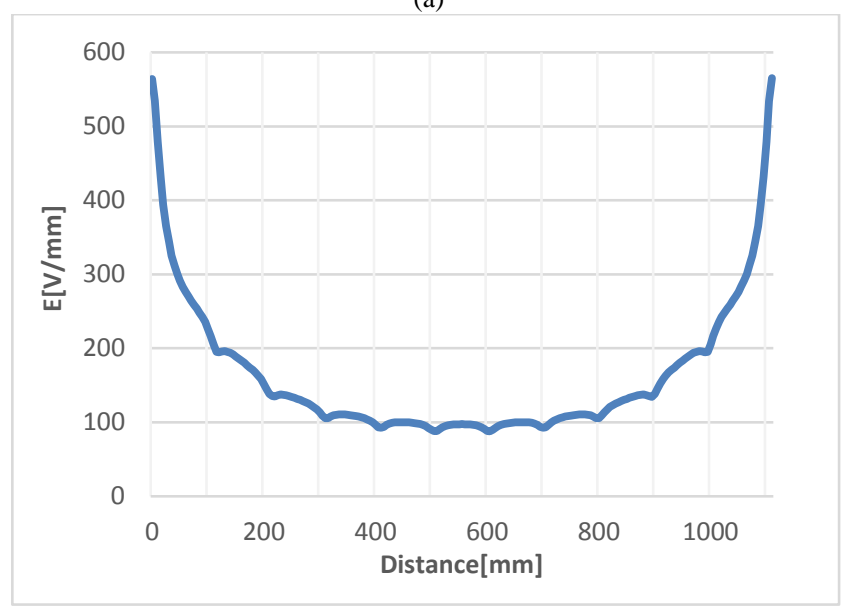

(b)

Fig.19 Simulated axial E-Field distribution along the surface of the rod: (a) with and (b) without embedded coil-resonators.

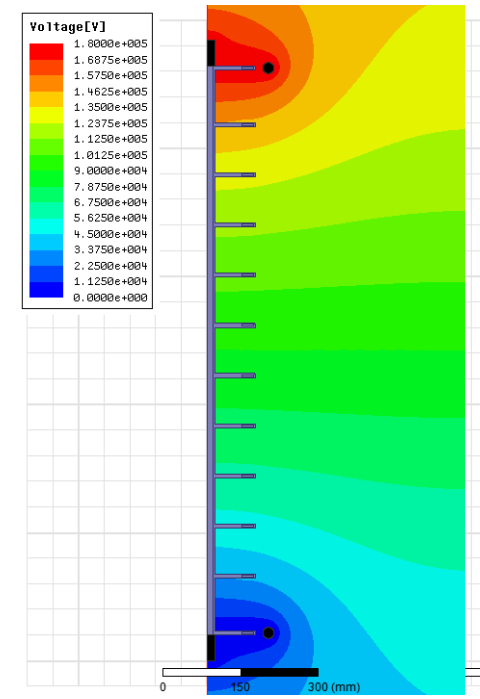

(a)

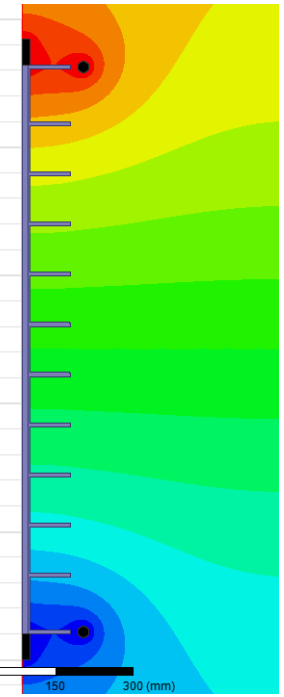

(b)
Fig.20 Simulated voltage distribution of the insulators: (a) with and (b) without the embedded coil-resonators.

\section{CONCLUSIONS}

This paper presents a novel concept of using a high-voltage insulation string structure with embedded coil-resonators for wireless power application. This idea is proposed for an industrial application of wireless power transfer for powering online monitoring system in high-voltage transmission networks. The WPT aspects of this idea have been studied with the help of a computer-aided analysis and practically verified. It has been found that over $25 \mathrm{~W}$ can be practically transferred over an overall transmission distance of $1.1 \mathrm{~m}$ at an energy efficiency exceeding $60 \%$. This amount of power is sufficient to meet the typical power requirement of $25 \mathrm{~W}$ in many existing online monitoring systems. This paper contains the first set of experimental results for this online monitoring application. A finite-element simulation on the electric field distribution has been conducted. The simulated results suggest no special problem in its high-voltage insulation capability. Further research is being conducted to evaluate the WPT capability in a high-voltage environment.

\section{ACKNOWLEDGMENT:}

S.Y.R. Hui and C. Zhang are grateful to the University of Hong Kong for its financial support for the US provisional patent application [21]. This work is supported by the Hong Kong Research Grant Council under the Project: 17255916. The practical power requirements of online monitoring systems are provided by Guangdong Power.

\section{REFERENCES}

[1] News article: "Blackouts hit 17 provinces", China.org.cn, 31 January, 2008 [online] http://www.china.org.cn/english/China/241448.htm

[2] News article: "Typhoon Mujigae kills 11 in South China, cuts off power", 6 October, 2015, [online] http://www.fmcoprc.gov.hk/eng/xwdt/jzzh/t1303777.htm

[3] X. Sun, Q. Huang, L. J. Jiang, and P.W. T. Pong, "Overhead HighVoltage Transmission-Line Current Monitoring by Magnetoresistive Sensors and Current Source Reconstruction at Transmission Tower", IEEE Trans. on Magnetics, Vol. 50, No. 1, Jan. 2014, paper: 4000405

[4] Kai Han, Hongrui Xu, "Research on Wireless Network-based Power Line Inspection”, 2009 International Forum on Information Technology and Applications, pp: 379-381

[5] X. Wang, , J. Hu, B. Wu, L. Du, Caixin Sun, "Study on Edge Extraction Methods for Image-based Icing On-line Monitoring on Overhead Transmission Lines", 2008 Int. Conf.on High Voltage Engineering and Application, Chongqing, China, Nov. 9-13, 2008, pp: 661-665

[6] T. Yin, X. Chen, Du Yan, Y. He, "Research on Power Supply Employed in Ices Real-Time Monitoring System of High-Voltage Transmission Lines", 2008 Int. Conference on High Voltage Engineering \& Application, Chongqing, China, Nov. 9-13, 2008, pp: 626-628

[7] Xinbo Huang and Xu Wei, "New On-line Monitoring Technology of Transmission Line Conductor Icing", 2012 IEEE Int. Conference on Condition Monitoring and Diagnosis, 23-27 Sept.2012, Bali, Indonesia, pp: $581-585$

[8] Jingbo Yang Zebing Dai Qingang Yu, "Online Monitoring of Windinduced Vibration of Transmission Steel High Tower", 2011 AsiaPacific Power and Energy Engineering Conf. (APPEEC), 25-28 March 2011, pp:1-4

[9] R. Holmukhe, P. Chaudhari, P. Kulkarni, K. Deshpande, P. Kulkarni, "Measurement of Weather Parameters via Transmission Line Monitoring System for Load Forecasting", 3rd Int. Conf. on Emerging Trends in Engineering and Technology, 2010, Pages: 298 - 303 
[10] S. Yang, H. Li, W. Zhou, J. Yu, "Lightning Current Waveform Observed on Transmission Line and Lightning Tower in China", 2014 Int. Conf. on Lightning Protection (ICLP), Shanghai, China, pp: 35-39

[11] Xinbo Huang, Wenjing Li, Ye Zhang, "Research of transmission line tower anti-theft monitoring technique based on video difference analysis", 8th International Conference on Wireless Communications, Networking and Mobile Computing (WiCOM), 2012, pp: 1-4

[12] R. Berthiaume and R. Blais, "Microwave repeater power supply tapped from the overhead ground wire on $735 \mathrm{kV}$ transmission lines," IEEE Trans. Power App. Syst., vol. PAS-99, no. 1, pp. 183-184, Jan./Feb. 1980.

[13] A. Kurs, A. Karalis, R. Moffatt, J. D. Joannopoulos, P. Fisher, and M. Soljacic, "Wireless power transfer via strongly coupled magnetic resonances," Science, vol. 317, no. 5834, pp. 83-86, Jul. 2007.

[14] S.Y.R. Hui, W.X. Zhong and C.K. Lee, "A critical review of recent progress in mid-range wireless power transfer", IEEE Transactions on Power Electronics, Vol. 29, No. 9, September 2014, pp:4500-4511

[15] S.Y.R. Hui and W.X. Zhong, "Apparatus and method for wireless power transfer", Patent application PCT/IB2011/000050, 14 January 2011

[16] W.X. Zhong, C.K. Lee and S.Y.R. Hui, "General analysis on the use of Tesla's resonators in domino forms for wireless power transfer", IEEE Transactions on Industrial Electronics, Vol.60, No.1, January 2013, pp: 261-270

[17] C.K. Lee, W.X. Zhong and S.Y.R. Hui, "Effects of magnetic coupling of non-adjacent resonators on wireless power domino-resonator systems", IEEE Transactions on Power Electronics, Volume: 27 , Issue: 4, 2012 , Page(s): $1905-1916$

[18] W.X. Zhong, C.K. Lee and S.Y.R. Hui, "Wireless power dominoresonator systems with non-coaxial axes and circular structures", IEEE Transactions on Power Electronics Volume: 27 , Issue: 11, 2012, Page(s): 4750 - 4762

[19] C. Zhang, N. Tang, W.X. Zhong, C.K. Lee and S.Y.R. Hui, "A new energy harvesting and wireless power transfer system for smart grid", IEEE 7th International Symposium on Power Electronics for Distributed Generation Systems (PEDG), 2016, Vancouver, Canada, 27-30 June, 2016

[20] IEC 60137 International Standard, Fifth edition, 2003, "Insulated bushings for alternating voltages above $1000 \mathrm{~V} "$.

[21] S.Y.R. Hui and C. Zhang, "A wireless power transfer system", U.S. Provisional Patent Application Serial No. 62/256,726, filed on November 18, 2015

[22] S. Babic, F. Sirois, C. Akyel, and C. Girardi, "Mutual inductance calculation between circular filaments arbitrarily positioned in space: Alternative to Grover's formula," IEEE Transactions on Magnetics, vol. 46, pp. 3591-3600, 2010.

[23] C. Zhang, W.X. Zhong, X. Liu and S.Y.R. Hui, "A fast method for generating time-varying magnetic flux patterns of mid-range wireless power transfer systems", IEEE Transactions on Power Electronics, Vol. 30, Issue 3, 2015, pp: 1513-1520.

[24] Website of Wishpower, http://wishpower.net/enproduct/show.asp?id=178

[25] S.Y.R. Hui, “"Magnetic Resonance for Wireless Power Transfer [A Look Back], IEEE Power Electronics Magazine, Vol. 3, Issue:1, 2016, pp: $14-31$

[26] C. Park; S. Lee; Gyu-Hyeong Cho; Chun T. Rim "Innovative 5-m-OffDistance Inductive Power Transfer Systems With Optimally Shaped Dipole Coils", IEEE Trans on Power Electronics, 2015, Volume: 30, Issue: 2 Pages: 817 - 827

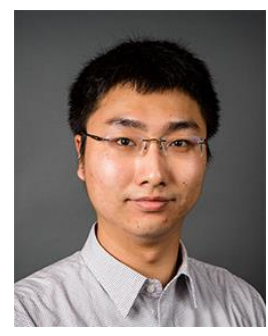

Cheng Zhang (S'13-M'16) was born in China, in 1990. He received the B.Eng. degree (first class Hons.) in electronic and communication engineering from the City University of Hong Kong, Kowloon, Hong Kong, in 2012, and the Ph.D. degree in electronic and electrical engineering from the University of Hong Kong, Hong Kong, in 2016. He was a senior research assistant in the department of electrical and electronic engineering, the University of Hong Kong from 2016 to 2017. He is currently a post-doctoral research associate in the research laboratory of electronics (RLE) at Massachusetts Institute of Technology.

His current research interests include high frequency AC-DC power conversions and designs and optimizations for wireless power transfer applications.

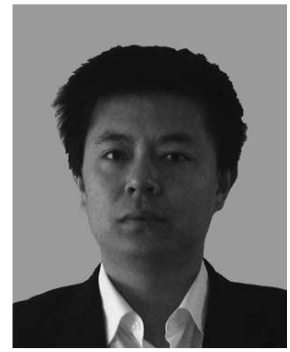

Deyan Lin (M'09) received the B.Sc. and M.A.Sc. degrees from Huazhong University of Science and Technology in 1995 and 2004, respectively, and the Ph.D. degree from the City University of Hong Kong in 2012.

$\mathrm{He}$ is currently a professor with the School of Automation, Wuhan University of Technology, Wuhan, and was a Post-doctoral Fellow with the Department of Electrical and Electronic Engineering, The University of Hong Kong. From 1995 to 1999, he was a Teaching Assistant in the Electrical Engineering Department at Jianghan University, Wuhan, where he became a Lecturer in 1999. From 2008 to 2009, he was a Senior Research Assistant with the City University of Hong Kong. His current research interests include wireless power transfer, memristors, modeling and control of gas-discharge lamps and light-emitting diode technology.

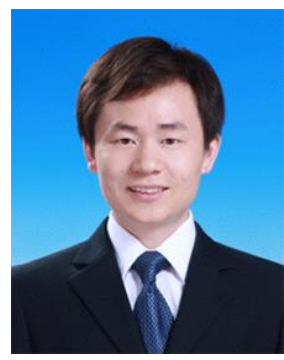

Niang Tang was born in Hunan, China in 1984. He received his B.S. degree and M.S. degree in electrical engineering in 2006 and 2009 respectively from Changsha University of Science and Technology, Changsha, China. He received his $\mathrm{Ph} . \mathrm{D}$. degree in electrical engineering in 2013 from North China Electric Power University, Beijing, China. Now, he is working with Electric Power Research Institute of Guangdong Power Grid Co., Ltd., Guangzhou, China. His research interests are in the area of power electronics and power quality.

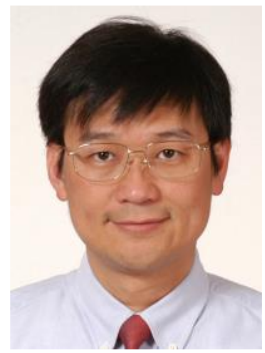

S. Y. Ron Hui (M'87-SM'94-F'03) received the B.Sc. (Eng.) Hons. degree from the University of Birmingham, Birmingham, U.K., in 1984 and the D.I.C. and Ph.D. degree in Electrical and Electronic Engineering from Imperial College London, London, U.K., in 1987.

He currently holds the Philip Wong Wilson Wong Chair Professorship at the University of Hong Kong, Pokfulam, Hong Kong, and a part-time Chair Professorship at Imperial College London. He has published over 300 technical papers, including more than 230 refereed journal publications. Over 60 of his patents have been adopted by industry. He is an Associate Editor of the IEEE TRANSACTIONS ON POWER ELECTRONICS and IEEE TRANSACTIONS ON INDUSTRIAL ELECTRONICS, and an Editor of the IEEE JOURNAL OF EMERGING AND SELECTED TOPICS IN POWER ELECTRONICS. His inventions on wireless charging platform technology underpin key dimensions of Qi, the world's first wireless power standard, with freedom of positioning and localized charging features for wireless charging of consumer electronics. Dr. Hui in November 2010 received the IEEE Rudolf Chope R\&D Award from the IEEE Industrial Electronics Society and the IET Achievement Medal (The Crompton Medal). He also received the 2015 IEEE William E. Newell Power Electronics Award. He is a Fellow of the Australian Academy of Technology \& Engineering and a Fellow of the Royal Academy of Engineering, U.K. 